\title{
Wireless Production Tools - PMSE - \\ Radio Spectrum Scanning at the Brazilian 2018 FIA Formula OneWorld Championship
}

\author{
Matthias Fehr \\ Mario Minami \\ Felipe Filgueiras \\ Pia Seeger \\ André F. Ponchet \\ Georg Fischer
}




\title{
Wireless Production Tools - PMSE - Radio Spectrum Scanning at the Brazilian 2018 FIA Formula One World Championship
}

\author{
Radio Spectrum Sharing and Regulation point of view \\ Matthias Fehr", Mario Minami ${ }^{\dagger}$, Felipe Filgueiras*, \\ Pia Seeger ${ }^{\dagger \dagger}$, Andre Fontoura Ponchet ${ }^{\dagger}$, Georg Fischer ${ }^{*}$ \\ *APWPT - Association of Professional Wireless Production Technologies, Postal Box 68, Baiersdorf, Germany \\ ${ }^{\dagger}$ CECS - Information Engineering, UFABC - Federal University of ABC, Santo Andre, SP, 09210-580, Brazil \\ *DTPD - Globo TV Group, Jardim Botanico, RJ, 22460-901, Brazil \\ Beuth University of Applied Science - Berlin, Germany \\ *FAU - Friedrich-Alexander University Erlangen - 91058 Erlangen, Nuremberg, Germany \\ e-mail: matthias.fehr@apwpt.org,mario.minami@ufabc.edu.br, felipe.costa@tvglobo.com.br, \\ pia.seeger@gmx.de, andre.ponchet@ufabc.edu.br, georg.fischer@fau.de
}

\begin{abstract}
Major international sporting competitions such as Formula 1 GP Championship offer a great opportunity to assess the use of the radio spectrum in many respects, such as operation, regulation, equipment, demands and conflicts between all involved professionals, content producers, technical support and local regulatory agencies. In this piece of work, spectral scanning measurements were performed in the range of 410 to $870 \mathrm{MHz}$, covering audio PMSE, e.g. wireless microphones, at the 2018 F1 GP Brazil from November $9^{\text {th }}$ to $11^{\text {th }}, 2018$. The spectral scanning equipment was installed at two different locations, the international technical area for the TV stations (compound) with the UFABC semi-portable $6 \mathrm{GHz}$ R\&S spectrum analyzer and in the TV Globo booth with APWPT's semi-portable R\&S spectrum analyzer in the middle of the pit line. There was a distance of about $2 \mathbf{k m}$ between the two locations and both sets of equipment were controlled by specialized software. The radio spectrum was in use by the race technical teams and the $\mathrm{TV}$ content production teams. Aside of the production, transmission and communication of data and content between the various teams and their car drivers, there was also a film crew in a helicopter, equipped with video cameras. At the three official days of the event, from November $9^{\text {th }}$ Friday to $11^{\text {th }}$ Sunday, during the initial numerous practice laps of the Interlagos racetrack, the official classification laps and the F1 GP Race itself, many links of audio PMSE were continuously monitored. Finally, the spectrum recordings were compared with TV Globo's coordination information (initial plan for assigning frequencies to wireless devices, the 'coordination table') to reduce errors in the evaluation of the spectrum recording. Using previous reports, produced since 2014, we can compare the number of microphone links used in the Brazilian F1 GP and contrast with similar recording procedures at the Italian F1 GP during the same period.
\end{abstract}

Index Terms - PMSE, Spectrum Scanning, Spectrum Occupancy, F1 Race, Spectrum Regulation, Spectrum Sharing, 4G/5G IMT, link density.

\section{INTRODUCTION}

The use of wireless production tools is constantly changing.
A sustainable trend is that more and more wireless applications are seeking access to spectrum. The focus of APWPT is the interference-free production of content and events in Art, Culture, Broadcast and the Creative Industry. Today, wireless production tools must combine ever higher production quality with the necessary flexibility, at a low cost. Most visitors to events and productions cannot see these tools. In addition, APWPT is actively involved in many working groups and supports them with carefully researched information. Part of this work is the close cooperation with many experienced teams in content and event production. The methodology for spectrum recording in the context of event production and the subsequent evaluation of the recorded data is a considerable challenge. This requires a scientifically consistent approach in combination with quality assurance methods - APWPT has learned this over many years. Therefore, APWPT is very grateful that universities from Brazil and Germany are supporting the work on foundations for consistent results.

This paper is organized as follows: section I - Introduction, with contextualize spectrum scanning and the measurements in Formula One with a quick explanation of the methodology; section II - Recording of Radio Spectrum in Sao Paulo, describes the measurements made at the 2018 Brazilian Formula 1 Grand Prix; section III - Evaluation of the observed Radio Spectrum use by PMSE, the analysis of recorded data and at the end, section IV finals Discussions and Conclusions.

Previous work

The initial ideas for spectrum recording and occupancy detection were sketched out in 2007 and initial spectrum recordings were carried out afterwards. Very quickly it became clear that the comparison of spectrum recordings of different events at different locations is a complex task. In addition, access to event production and the installation of antennas and scanner technology is challenging. Here the practical access 
conditions very often deviate from technically reasonable schemes. Together with our supporting organizations, APWPT has presented and discussed to the public the slowly developing methodology. The experience gained was transferred into an ever-improved methodology and programmed into free software: the "PMSE Occupation Recorder".

Spectrum recordings in the context of Formula One

RAI's production team in Italy has been performing spectrum recording for several years despite limited resources. Representative results could be presented in the context of the European Microwave Week [1]. PMSE Workshops at EuMW conferences have been held annually at various locations since 1998 and is a special scientific highlight of public relations work).

A particularly interesting question was whether the spectrum occupancy by wireless production tools in Brazil differs considerably from that in Europe. With the support of European contacts to the Formula 1 team, the necessary preparations were started. One necessary action was the comparison of the frequency coordination information of Formula 1 productions. What is frequency coordination information? Is the initial plan for assigning frequencies to wireless devices turned into reality? How much tweaking and deviation from initial plans happens during an event? Every commercial event production optimizes, partly over months or years, the access to radio frequencies by wireless production tools. In the process, locally available frequencies and the needs of event production are compared and optimized. During International Broadcasting Convention - IBC2018 [2] , September 2018 in Amsterdam, multi-year coordination information from Brazil and Italy was presented [3]. Figure 1 shows an update of the presented coordination information of Audio PMSE [4] where we can note an interesting trend difference. The number of coordinated audio links is increasing in Italy and in Brazil. The following look into the spectrum recordings shows the probable cause.

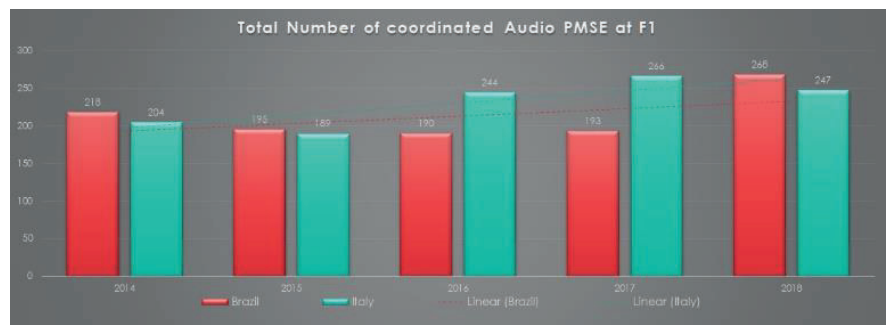

Figure 1: comparison of frequency coordination data over several years (data source: Globo TV and RAI)

Brief intro to spectrum recording methodology Automatic level correction

The signal strength of the reception level at the scanner input frequently exceeds the scanner dynamic range. The scanner-input attenuation is therefore automatically adjusted to the local situation by the spectrum scanning software operated on an external computer. The scanning data contains information on the setting of variable input attenuator, but the recorded level is not modified. During the data analysis, the recorded dynamic range will be recreated as close to reality as possible. On the bottom of the output graphic this is noted with 'True recorded signal' or 'Chart re-calculated at the bottom area by up to $L_{\max } d B$ ' (where $L_{\max }$ represents the maximum value of the level correction).

\section{Recording of scanned spectrum data}

It is of special concern during spectrum recordings to store the recorded data as transparently as possible. Therefore, a special method of data storage has been chosen. Each scan cycle is stored in a new ASCII file - indicated as log files in tables 2 and 4 - and, in addition to the scan data, contains important metadata for subsequent data evaluation.

\section{Summary of some advantages of the methodology:}

- Each data set can be imported into Excel or similar tools and evaluated separately.

- Each record contains important data project identification.

- Each record contains information for comprehensive analysis, such as the measurement bandwidth.

- Each record contains information that the scan has been completed or that the input attenuator was changed.

- If available, record will contain the location coordinates.

- If available, each data set contains information on antenna cable attenuation, filter attenuation, or gain from external components inserted before the scanner input.

- Each record contains the number of scan stations and its own scanner number.

- Multiple scanners' data can be combined by data fusion.

Previously known disadvantages:

- $\quad$ Speed of data storage and loading is reduced compared to binary single file recording.

- The maximum number of scans is limited to the Windows operating system or the hard disk file system.

- In practice, however, scans with more than 400,000 individual files were evaluated on computers with Windows 7 or Windows 10 (both in 64-bit version).

How is each single spectrum scan performed?

Depending on the examined frequency range, the necessary scanner bandwidth and scanner detectors are selected at the beginning of spectrum recording.

\section{Example for the UHF TV range:}

- For the frequency range 470 to $862 \mathrm{MHz}$, the main scan is performed with a resolution bandwidth of $100 \mathrm{kHz}$ and an RMS detector. In addition, a reduced bandwidth of $30 \mathrm{kHz}$ can also be used on request. This reduction allows the detection of relatively narrowband reception signals but requires significantly more time for the scan. The frequency step size of these scans is $20 \mathrm{kHz}$.

- A different scan bandwidth is used for the frequency range 410 to $470 \mathrm{MHz}$. Since in the frequency range 410 to 470 $\mathrm{MHz}$ mostly narrow-band links are operated, a bandwidth 
of $30 \mathrm{kHz}$ is used here. The range $470-870 \mathrm{MHz}$ is again recorded with $100 \mathrm{kHz}$ bandwidth. The frequency step size of these scans is $10 \mathrm{kHz}$.

- Additional scan with large bandwidth. After each single scan with 30 or $100 \mathrm{kHz}$ bandwidth, an additional scan with a bandwidth of $10 \mathrm{MHz}$ is performed (not supported by every scanner). In each single scan, the power levels of all recorded signals are added together. This sum power is the criterion for controlling the input attenuator of the scanner. After many test series it was possible to find a compromise between the avoidance of a level overdrive of the scanner receiver and its possibly reduced sensitivity.

\section{RECORdING OF RADIO SPECTRUM In SAO PAULO}

The spectrum recording took place over a period of three days. On the first day, the frequency range from 410 to $870 \mathrm{MHz}$ was recorded. On the second and third day only the frequency range 470 to $862 \mathrm{MHz}$ was recorded. This allowed for frequency scans to be performed with shorter time intervals. In addition, we had to use a different measuring antenna at the $1^{\text {st }}$ scan station from the second day on. The new antenna only supported 470 to $862 \mathrm{MHz}$.

The spectrum scans were conducted jointly with the Federal University of ABC (UFABC). The regional broadcaster Globo TV (DTPD) provided access to two different locations at the Autodromo José Carlos Pace [5], marked by yellow pins at figure 2 .

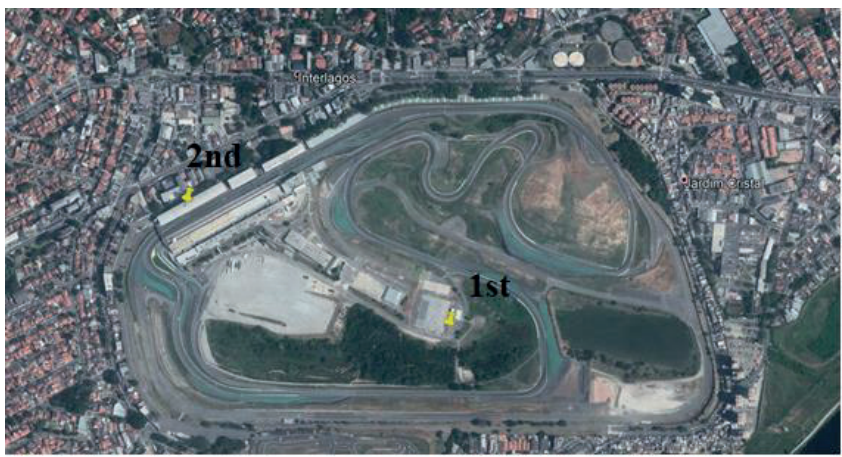

Figure 2: locations of the spectrum recordings during F1 - Sao Paulo (source: Google Maps)

Locations of the scan stations

According figure 2, the two recording stations were located at:

- $\quad 1^{\text {st }}$ Station: GPS latitude $=-23.701117^{\circ} /$ GPS longitude $=-46.695833^{\circ}$

- $\quad 2^{\text {nd }}$ Station: GPS latitude $=-23.705283^{\circ} /$ GPS longitude $=-46.699717^{\circ}$

The figure 3 shows the race track altitude profile.

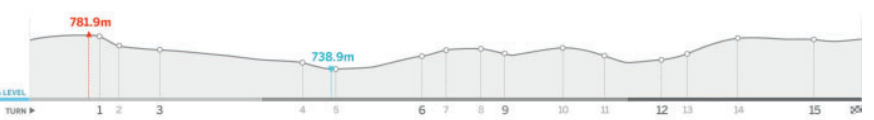

Figure 3: elevation changes at Autodromo José Carlos Pace. Source: [6].

\section{Measuring instruments used for spectrum recording}

- $\quad 1^{\text {st }}$ Station, Responsible: Federal University of ABC (UFABC) Equipment: Rohde\&Schwarz, FSL-6, 100691/016, 1.91 Antenna: A2003, Omnidirectional antenna, vertically polarized

- $\quad 2^{\text {nd }}$ Station, Responsible: Association of Professional Wireless
Production Technologies e. V.

Equipment: Rohde\&Schwarz, FSL-3, 101308/003, 1.90

Antenna: SD3000, Wide-band antenna, vertically polarized.

Pictures of the scanner's installation

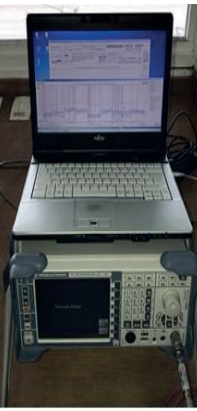

Figure 4: second scan station

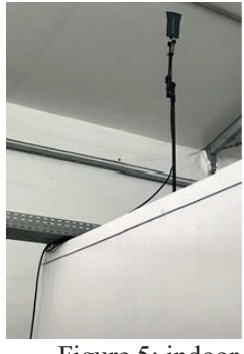

Figure 5: indoor antenna of $1^{\text {st }}$ scan station

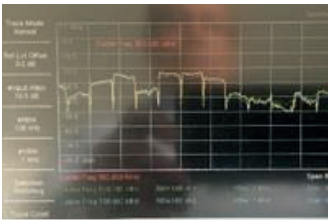

Figure 6: spectrum plot of a hand-held scanner

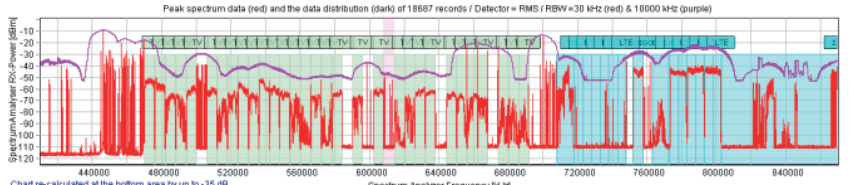

Figure 7: recorded spectrum allocation 410-870 MHz - frequency domain (18686 data records)

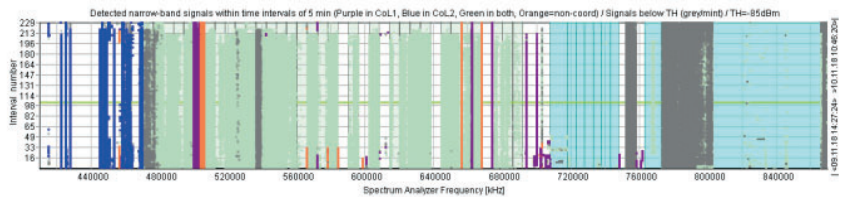

Figure 8: recorded spectrum allocation 410-870 MHz - time domain (18686 data records)
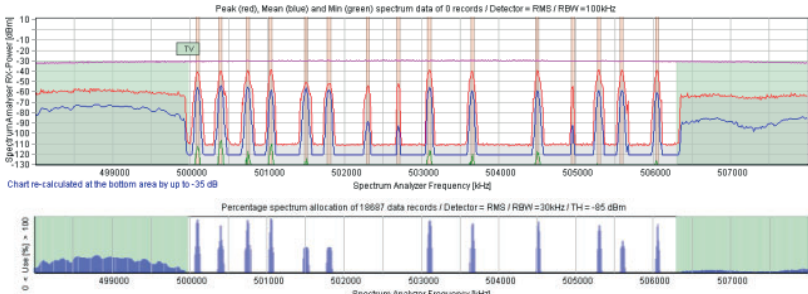

111111] I III]

Figure 9-11: 15 detected links in 498-508 $\mathrm{MHz}$ and their level variance (18686 data records)

From the second day of the spectrum scans onwards a high pass filter was inserted at the antenna input connector of the second scanner station. This reduced the level of strong signals below $470 \mathrm{MHz}$ and allowed the scanner above to support a better use of the limited receiver dynamic range.

Figure 7 illustrates the aggregated spectrum recording in frequency domain from both scanners, performed on first day while figure 8 illustrates the time domain.

On the first day, a spectrum scan was performed in the enlarged frequency range from $410 \mathrm{MHz}$ to $862 \mathrm{MHz}$. Thus, two important topics could be addressed, i.e. Checking the functionality of both scan stations and generating an overview of frequency usage below $470 \mathrm{MHz}$.

Figures 9-12 show parts of the frequency recordings that represent the signals recorded by them. 
These pictures show exemplarily the substantial signal dynamics, which can occur in the event production. Tables 1 and 2 summarize the recorded spectrum information measured on the first day and tables 3 and 4 summarize the spectrum information captured on second and third day.

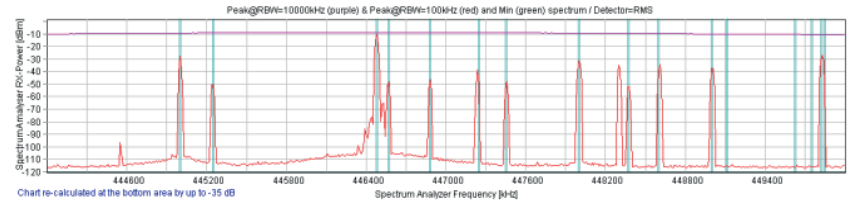

Figure 12: 13 detected links in 444-450 MHz and their level variance > $100 \mathrm{~dB}$ (18686 data records)

Table 1 - Brief summary of the recorded spectrum information ${ }^{(\mathrm{e})}, 1^{\text {st }}$ day

\begin{tabular}{|c|c|}
\hline Description & Spec Information \\
\hline Scanned frequency band & 410 to $870 \mathrm{MHz}$ \\
\hline Range of scanned frequency band & $460 \mathrm{MHz}$ \\
\hline TV channels in use by Broadcast & 31 \\
\hline Radio spectrum in use by Broadcast & $186 \mathrm{MHz}$ \\
\hline LTE channels in use by IMT ${ }^{(f)}$ & 12 \\
\hline Radio spectrum in use by IMT & $60 \mathrm{MHz}$ \\
\hline Radio spectrum in use by non-PMSE WB sys & $83 \mathrm{MHz}$ \\
\hline Radio spectrum in use by WB PMSE systems & $10 \mathrm{MHz}$ \\
\hline Radio spectrum remaining NB and WB PMSE & $141 \mathrm{MHz}$ \\
\hline Radio spectrum below $470 \mathrm{MHz}$ (TalkBack) & $60 \mathrm{MHz}$ \\
\hline NB PMSE detected in $410-870 \mathrm{MHz}$ & 97 \\
\hline NB PMSE detected in $410-470 \mathrm{MHz}$ & 54 \\
\hline NB PMSE detected in $470-870 \mathrm{MHz}$ & 43 \\
\hline NB PMSE manually marked outside TV ch & 56 \\
\hline NB PMSE manually marked in $410-470 \mathrm{MHz}$ & 43 \\
\hline NB PMSE manually marked in TV channels & 4 \\
\hline Spectrum for detected PMSE in $410-470 \mathrm{MHz}^{(\mathrm{a})(\mathrm{b})}$ & 4.9 MHz/97 Links \\
\hline Spectrum for detected PMSE in $470-870 \mathrm{MHz}^{(\mathrm{c})(\mathrm{d})}$ & $30.5 \mathrm{MHz} / 60$ links \\
\hline Required spectrum for NB and WB PMSE ${ }^{(b)}$ & $45.4 \mathrm{MHz}$ \\
\hline Spec density of all detected PMSE in $410-870 \mathrm{MHz}^{(\mathrm{b})}$ & 1.135 Links/MHz \\
\hline Spec density of detected NB PMSE in $410-870 \mathrm{MHz}^{(\mathrm{b})}$ & 1.113 Links/MHz \\
\hline Spec density of detected NB PMSE in $410-470 \mathrm{MHz}^{(\mathrm{b})}$ & 1.617 Links/MHz \\
\hline Spec density of detected NB PMSE in $470-870 \mathrm{MHz}^{(\mathrm{b})}$ & $0.741 \mathrm{Links} / \mathrm{MHz}$ \\
\hline Coordinated PMSE in the scanned freq band & 269 \\
\hline Coordinated NB PMSE in the scanned band & 266 \\
\hline Coordinated audio PMSE in WB systems & 2 \\
\hline Coordinated video PMSE in WB systems & 1 \\
\hline Coordinated NB PMSE in 410-470 MHz & 88 \\
\hline Coordinated NB PMSE in 470-870 MHz & 178 \\
\hline Spec density of all coordinated PMSE in $410-870 \mathrm{MHz}$ & 0.585 Links/MHz \\
\hline Spec density of coordinated NB PMSE in $410-470 \mathrm{MHz}$ & 1.467 Links/MHz \\
\hline Spec density of all coordinated PMSE in $470-870 \mathrm{MHz}$ & 0.453 Links $/ \mathrm{MHz}$ \\
\hline Spec density of coordinated NB PMSE in $470-870 \mathrm{MHz}$ & 0.445 Links $/ \mathrm{MHz}$ \\
\hline \multicolumn{2}{|c|}{ Calculation bases on a $50 \mathrm{kHz}$ grid and two additional $25 \mathrm{kHz}$ guard bands } \\
\hline \multicolumn{2}{|c|}{$\begin{array}{l}\text { c) Calculation bases on a } 500 \mathrm{kHz} \text { grid and two additional } 250 \mathrm{kHz} \text { guard bands and considers } \\
\text { manually marked links }\end{array}$} \\
\hline $\begin{array}{l}\text { This calculation does not consider required guard } \\
\text { Stat software version: PMSE Occupation Recorde }\end{array}$ & \\
\hline
\end{tabular}

Some environment pictures are presented in figures 13 to 15. Figure 16 illustrates the aggregated spectrum recording in frequency domain obtained from both scanners, performed on second and third day while figure 17 illustrates the time domain.

On the second and third day the frequency range 470-862 $\mathrm{MHz}$ was recorded. The aggregated signal spectrum shows a rarely occurring dense frequency usage. Figures 18 to 20 show

a selected frequency range and the signals recorded in it are shown again.

Table 2 - Minimum and Maximum receiver input level ${ }^{(a)}, 1^{\text {st }}$ day

\begin{tabular}{|l|c|c|l|}
\hline $\begin{array}{l}\text { Information } \\
\text { on receiver } \\
\text { input level }\end{array}$ & $\begin{array}{l}\text { Freq. } \\
\text { Level@ } \\
\text { RBW }\end{array}$ & level & \multicolumn{1}{|c|}{ Log file } \\
\hline $\begin{array}{l}\text { Max } \\
\text { scanning }\end{array}$ & $30 \mathrm{kHz}$ & $-10.21 \mathrm{dBm}$ & $\begin{array}{l}\text { Scan1110180932371970.txt at } \\
446480 \mathrm{kHz}\end{array}$ \\
\cline { 2 - 4 } & $10 \mathrm{MHz}$ & $-9.06 \mathrm{dBm}$ & $\begin{array}{l}\text { Scan1110180927486873.txt at } \\
446130 \mathrm{kHz}\end{array}$ \\
\hline Min scanning & $30 \mathrm{kHz}$ & $-123.92 \mathrm{dBm}$ & $\begin{array}{l}\text { Scan1 109182020217319.txt at } \\
439530 \mathrm{kHz}\end{array}$ \\
\hline $\begin{array}{l}\text { Max on 1st } \\
\text { scanner }\end{array}$ & $100 \mathrm{kHz}$ & $-10.21 \mathrm{dBm}$ & $\begin{array}{l}\text { Scan1110180932371970.txt at } \\
446480 \mathrm{kHz}\end{array}$ \\
\hline $\begin{array}{l}\text { Min on 1st } \\
\text { scanner }\end{array}$ & $100 \mathrm{kHz}$ & $-112.69 \mathrm{dBm}$ & $\begin{array}{l}\text { Scan1110180524505408.txt at } \\
491980 \mathrm{kHz}\end{array}$ \\
\hline $\begin{array}{l}\text { Max on 2nd } \\
\text { scanner }\end{array}$ & $100 \mathrm{kHz}$ & $-13.72 \mathrm{dBm}$ & $\begin{array}{l}\text { Scan1 109181657425772.txt at } \\
700100 \mathrm{kHz}\end{array}$ \\
\hline $\begin{array}{l}\text { Min on 2nd } \\
\text { scanner }\end{array}$ & $100 \mathrm{kHz}$ & $-123.92 \mathrm{dBm}$ & $\begin{array}{l}\text { Scan1 109182020217319.txt at } \\
439530 \mathrm{kHz}\end{array}$ \\
\hline \multicolumn{3}{|c|}{ Maximum scanner input attenuator position: 20 dB } \\
\hline \multicolumn{2}{|c|}{ Stat software version: PMSE Occupation Recorder R6.3.15a }
\end{tabular}

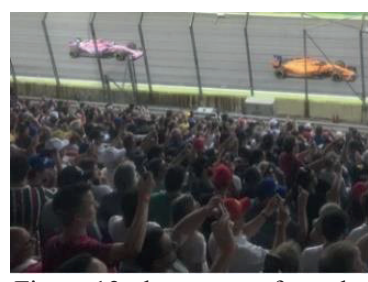

Figure 13: the car race from the visitors' point of view

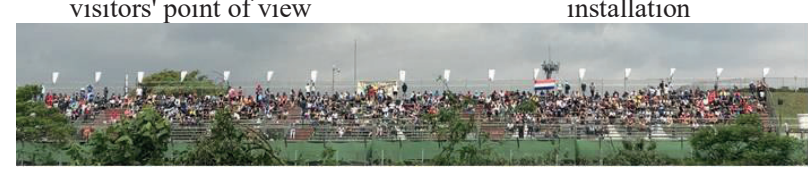

Figure 15: view into one of several visitor areas

The figure 21 shows the combined frequency usage by LTE (IMT), an ENG/OB system and narrow band PMSE links.

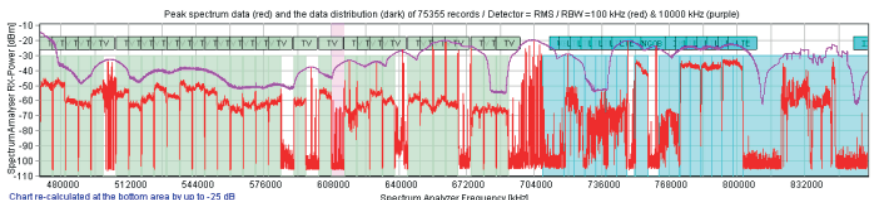

Figure 16: recorded spectrum allocation $410-870 \mathrm{MHz}$ - frequency domain (75354 data records)

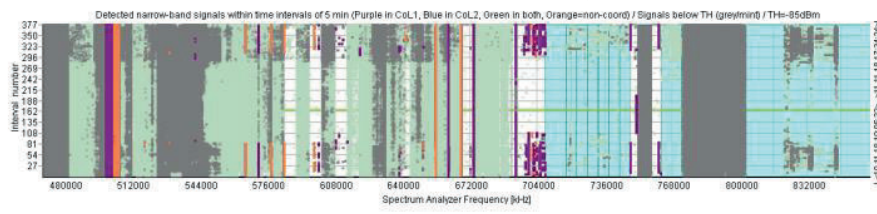

Figure 17: recorded spectrum allocation $410-870 \mathrm{MHz}$ - frequency domain (75354 data records)
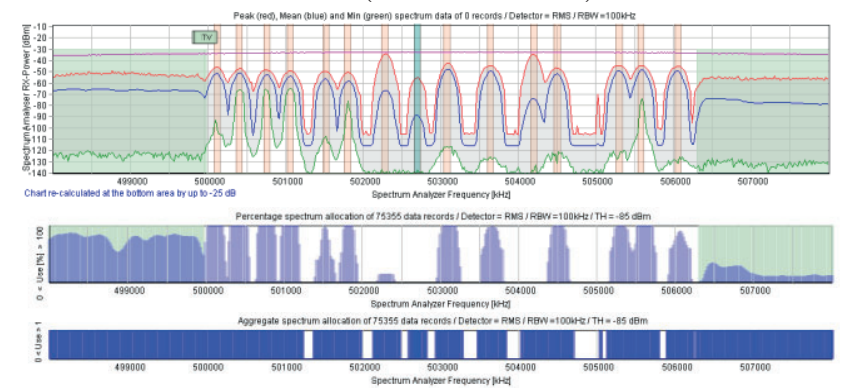

Figures 18-20: example of 14 detected and 1 manually marked links in 498-508 MHz and their level variance (75354 data records) 


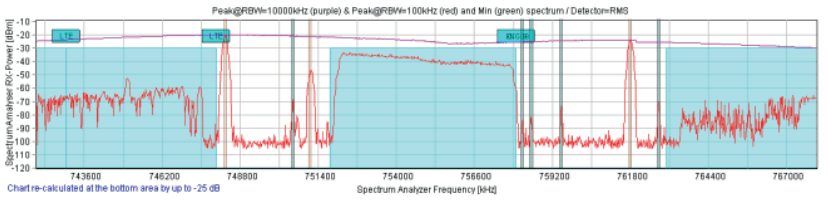

Figure 21: example of 3 detected, 5 manually marked narrow-band links and 1 wide-band ENG/OB in the $700 \mathrm{MHz}$ duplex gap

Table 3 - Brief summary of the recorded spectrum information ${ }^{(\mathrm{c})}, 2^{\text {nd }}$ and $3^{\text {rd }}$ day

\begin{tabular}{|c|c|}
\hline Description & Spec Information \\
\hline Scanned frequency band & 470 to $862 \mathrm{MHz}$ \\
\hline Range of scanned frequency band & $392 \mathrm{MHz}$ \\
\hline TV channels in use by Broadcast & 31 \\
\hline Radio spectrum in use by Broadcast & $186 \mathrm{MHz}$ \\
\hline LTE channels in use by IMT & 12 \\
\hline Radio spectrum in use by IMT & $60 \mathrm{MHz}$ \\
\hline Radio spectrum in use by non-PMSE WB sys & $75 \mathrm{MHz}$ \\
\hline Radio spectrum in use by WB PMSE systems & $10 \mathrm{MHz}$ \\
\hline Radio spec remaining for NB and WB PMSE & $81 \mathrm{MHz}$ \\
\hline Radio spectrum below $470 \mathrm{MHz}$ (TalkBack) & $60 \mathrm{MHz}$ \\
\hline NB PMSE detected outside of TV channels & 51 \\
\hline NB PMSE manually marked outside TV ch & 23 \\
\hline NB PMSE manually marked in TV channels & 3 \\
\hline Required spectrum for detected NB PMSE ${ }^{\text {(a) }}$ & $39.00 \mathrm{MHz} / 77$ Links \\
\hline Required spectrum for NB and WB PMSE ${ }^{(b)}$ & $49.00 \mathrm{MHz}$ \\
\hline Spectrum density of detected NB PMSE ${ }^{(b)}$ & 0.951 Links $/ \mathrm{MHz}$ \\
\hline Coordinated PMSE in the scanned freq band & 162 \\
\hline Coordinated NB PMSE in the scanned band & 159 \\
\hline Coordinated audio PMSE in WB systems & 2 \\
\hline Coordinated video PMSE in WB systems & 1 \\
\hline Spec density of all coordinated PMSE & 2.000 Links/MHz \\
\hline \multicolumn{2}{|c|}{$\begin{array}{l}\text { (a) Calculation bases on a } 500 \mathrm{kHz} \text { grid and two additional } 250 \mathrm{kHz} \text { guard bands and manually } \\
\text { marked links. This calculation does not consider required guard bands to TV or IMT channels } \\
\text { (b) Calculation considers manually marked links } \\
\text { (c) Stat software version: PMSE Occupation Recorder R6.3.15a }\end{array}$} \\
\hline
\end{tabular}

Table 4 - Minimum and Maximum receiver input level ${ }^{(a)}, 2^{\text {nd }}$ and $3^{\text {rd }}$ day

\begin{tabular}{|l|c|c|l|}
\hline $\begin{array}{l}\text { Information } \\
\text { on receiver } \\
\text { input level }\end{array}$ & $\begin{array}{l}\text { Freq } \\
\text { Level@ } \\
\text { RBW }\end{array}$ & level & \multicolumn{1}{c|}{ Log file } \\
\hline \multirow{2}{*}{$\begin{array}{l}\text { Maximum } \\
\text { scanning }\end{array}$} & $100 \mathrm{kHz}$ & $-20.21 \mathrm{dBm}$ & $\begin{array}{l}\text { Scan1110181704591002.txt at } \\
748300 \mathrm{kHz}\end{array}$ \\
\cline { 2 - 4 } & $10 \mathrm{MHz}$ & $-14.2 \mathrm{dBm}$ & $\begin{array}{l}\text { Scan1111181132437624.txt at } \\
468360 \mathrm{kHz}\end{array}$ \\
\hline $\begin{array}{l}\text { Minimum } \\
\text { scanning }\end{array}$ & $100 \mathrm{kHz}$ & $-120.14 \mathrm{dBm}$ & $\begin{array}{l}\text { Scan1111181024319771.txt at } \\
706540 \mathrm{kHz}\end{array}$ \\
\hline $\begin{array}{l}\text { Max on 1st } \\
\text { scanner }\end{array}$ & $100 \mathrm{kHz}$ & $-20.21 \mathrm{dBm}$ & $\begin{array}{l}\text { Scan1110181704591002.txt at } \\
748300 \mathrm{kHz}\end{array}$ \\
\hline $\begin{array}{l}\text { Min on 1st } \\
\text { scanner }\end{array}$ & $100 \mathrm{kHz}$ & $-120.14 \mathrm{dBm}$ & $\begin{array}{l}\text { Scan1111181024319771.txt at } \\
706540 \mathrm{kHz}\end{array}$ \\
\hline $\begin{array}{l}\text { Max on 2nd } \\
\text { scanner }\end{array}$ & $100 \mathrm{kHz}$ & $-25.85 \mathrm{dBm}$ & $\begin{array}{l}\text { Scan1110181202488294.txt at } \\
641720 \mathrm{kHz}\end{array}$ \\
\hline $\begin{array}{l}\text { Min on 2nd } \\
\text { scanner }\end{array}$ & $100 \mathrm{kHz}$ & $-118.35 \mathrm{dBm}$ & $\begin{array}{l}\text { Scan1111181041047556.txt at } \\
805480 \mathrm{kHz}\end{array}$ \\
\hline \multicolumn{3}{|c|}{ Maximum scanner input attenuator position: $10 \mathrm{~dB}$} \\
\hline
\end{tabular}

III. EVAlUATION OF THE OBSERVED RADIO SPECTRUM USE BY PMSE

In addition to the comprehensive data recorded in Sao Paulo or available as coordination information, additional data were available from the Formula One productions in Monza [3] in 2017 and 2018. Table 5 compares the available information (Please pays attention to technical notes below the table.)

Use of PMSE in the gaps between TV channels

A special usage scenario was observed in Sao Paulo - the operation of Audio PMSE between occupied TV channels.

Figures 22 and 23 show a typical situation, PMSEs operated in the gaps between digital TV channels. This operation of PMSE in the gaps between television channels is assessed as a critical scenario.

The scan antenna of the first scan station was in a large fabric tent. The fabric surface of this tent was coated with a thin layer of metal. Therefore, an additional path attenuation of about $6 \mathrm{~dB}$ is estimated.

Table 5: Comparison of coordination information and detected PMSE links

\begin{tabular}{|c|c|c|c|}
\hline Category & Brazil 2018 & Italy 2017 & Italy 2018 \\
\hline $\begin{array}{l}\text { Number of coordinated PMSE } \\
\text { links in } 410-870 \mathrm{MHz}\end{array}$ & 269 & 269 & 247 \\
\hline $\begin{array}{l}\text { Number of coordinated PMSE } \\
\text { links in } 410-470 \mathrm{MHz}\end{array}$ & 88 & 45 & $\mathrm{~N} / \mathrm{A}^{(2)}$ \\
\hline $\begin{array}{l}\text { Number of coordinated PMSE } \\
\text { links in } 470-870 \mathrm{MHz}\end{array}$ & $\begin{array}{l}178+3 \text { in } \\
\text { WB links }\end{array}$ & 224 & $\mathrm{~N} / \mathrm{A}^{(2)}$ \\
\hline $\begin{array}{l}\text { Radio spectrum in use by } \\
\text { Broadcast }\end{array}$ & $186 \mathrm{MHz}$ & $48 \mathrm{MHz}$ & 88 \\
\hline $\begin{array}{l}\text { Radio spectrum in use by IMT } \\
\text { and non-PMSE wb. systems }\end{array}$ & $143 \mathrm{MHz}$ & $60 \mathrm{MHz}$ & 60 \\
\hline $\begin{array}{l}\text { Radio spectrum remaining for } \\
\text { PMSE in } 410-870 \mathrm{MHz}^{(1)}\end{array}$ & $141 \mathrm{MHz}$ & $352 \mathrm{MHz}$ & 318 \\
\hline $\begin{array}{l}\text { Spectrum density of all coordinated } \\
\text { PMSE in } 410-870 \mathrm{MHz}^{(1)}\end{array}$ & $\begin{array}{l}\text { 1.135 Links/ } \\
\mathrm{MHz}\end{array}$ & $\begin{array}{c}0.585 \text { Links/ } \\
\mathrm{MHz}\end{array}$ & $\mathrm{N} / \mathrm{A}^{(2)}$ \\
\hline $\begin{array}{l}\text { Spectrum density of all coordinated } \\
\text { PMSE in } 410-470 \mathrm{MHz}^{(1)}\end{array}$ & $\begin{array}{c}\text { 1.617 Links/ } \\
\mathrm{MHz}\end{array}$ & $\begin{array}{c}0.750 \text { Links/ } \\
\mathrm{MHz}\end{array}$ & $\mathrm{N} / \mathrm{A}^{(2)}$ \\
\hline $\begin{array}{l}\text { Spec density of all coordinated } \\
\text { PMSE in } 470-870 \mathrm{MHz}^{(1)}\end{array}$ & $\begin{array}{l}\text { 0.741 Links/ } \\
\mathrm{MHz}\end{array}$ & $\begin{array}{l}0.560 \mathrm{Links} / \\
\mathrm{MHz}\end{array}$ & $\mathrm{N} / \mathrm{A}^{(2)}$ \\
\hline $\begin{array}{l}\text { Spectrum density of all detected } \\
\text { PMSE in } 410-870 \mathrm{MHz}^{(1)}\end{array}$ & $\begin{array}{l}0.585 \mathrm{Links}^{(1} \\
\mathrm{MHz}^{(4)}\end{array}$ & $\mathrm{N} / \mathrm{A}^{(3)}$ & $\begin{array}{l}0.390 \text { Links/ } \\
\mathrm{MHz}^{(5)}\end{array}$ \\
\hline $\begin{array}{l}\text { Spectrum density of detected NB } \\
\text { PMSE in } 410-870 \mathrm{MHz}^{(1)}\end{array}$ & $\begin{array}{c}0.453 \text { Links/ } \\
\mathrm{MHz}^{(4)}\end{array}$ & $\begin{array}{c}0.455 \text { Links/ } \\
\mathrm{MHz}^{(5)}\end{array}$ & $\begin{array}{c}0.390 \text { Links/ } \\
\mathrm{MHz}^{(5)}\end{array}$ \\
\hline $\begin{array}{l}\text { Spectrum density of detected NB } \\
\text { PMSE in } 410-470 \mathrm{MHz}^{(1)}\end{array}$ & $\begin{array}{l}1.467 \mathrm{Links}^{(4)} \\
\mathrm{MHz}^{(4)}\end{array}$ & $\begin{array}{l}\text { 1.183 Links/ } \\
\mathrm{MHz}^{(5)}\end{array}$ & $\begin{array}{l}0.717 \mathrm{Links} / \\
\mathrm{MHz}^{(5)}\end{array}$ \\
\hline $\begin{array}{l}\text { Spectrum density of detected NB } \\
\text { PMSE in } 470-870 \mathrm{MHz}^{(1)}\end{array}$ & $\begin{array}{c}0.445 \text { Links/ } \\
\mathrm{MHz}^{(4)}\end{array}$ & $\begin{array}{c}0.305 \text { Links/ } \\
\mathrm{MHz}^{(5)}\end{array}$ & $\begin{array}{c}0.302 \text { Links/ } \\
\mathrm{MHz}^{(5)}\end{array}$ \\
\hline $\begin{array}{l}\text { Spectrum density of detected NB } \\
\text { PMSE in } 470-870 \mathrm{MHz}^{(1)}\end{array}$ & $\begin{array}{l}0.951 \mathrm{Links}^{(6)} \\
\mathrm{MHz}^{(6)}\end{array}$ & $\begin{array}{c}0.305 \text { Links/ } \\
\mathrm{MHz}^{(5)}\end{array}$ & $\begin{array}{l}0.302 \text { Links/ } \\
\mathrm{MHz}^{(5)}\end{array}$ \\
\hline
\end{tabular}

(1) This calculation does not consider required guard bands from PMSE to TV or IMT channels.

No detailed coordination information available.

No wide-band PMSE inks detected.

${ }^{4)}$ Considers only links that were detected on 1 st day.

(5) Relatively small number of spectrum scans allows only a limited comparison of the results.

(6) Considers only links that were detected on 2nd to 3rd day.

The zoomed scans in figures 24 and 25 show the spectrum use in an unoccupied TV channel between two occupied TV channels.

\section{Comparison of the recorded signals: location 1 and location 2}

The spectral scanning equipment was installed at two different locations, at location 1 - the international technical area for the TV stations (compound) with the UFABC semiportable $6 \mathrm{GHz}$ R\&S spectrum analyser shown in figure 26 and at location 2 - the TV Globo booth with APWPT's semiportable $3 \mathrm{GHz}$ R\&S spectrum analyser in the middle of the pit line, shown in figure 27.

The scan antenna of the first scan station was in a large fabric tent. The fabric surface of this tent was coated with a thin layer of metal. Therefore, an additional path attenuation of about $6 \mathrm{~dB}$ is estimated.

Figure 28 shows the final output of the aggregation of all scans from all locations.

The possible effect of high network density of TV transmitters for the production quality of Audio PMSE

In Sao Paulo, the signals from 31 TV stations were recorded. In this section, we try to specify the signal level of the TV transmitters at the receiver input of the audio PMSE. 
The red line in figure 29 shows the signal level measured in a bandwidth of $100 \mathrm{kHz}$ and the purple line refers to a bandwidth of $10 \mathrm{MHz}$ - both measured with RMS detector - a level up to $-38 \mathrm{dBm}$. Considering the crest factor of the TV signal, the maximum peak interferer level is expected to be significantly above $-30 \mathrm{dBm}$.

\section{Effect of the antenna polarization}

As Globo DTPD staff noted, the polarization in Brazil by regulation is horizontal for the reception, so all broadcasters use horizontal transmission or elliptical polarization. Because the scan antennas had a vertical polarization, a higher reception
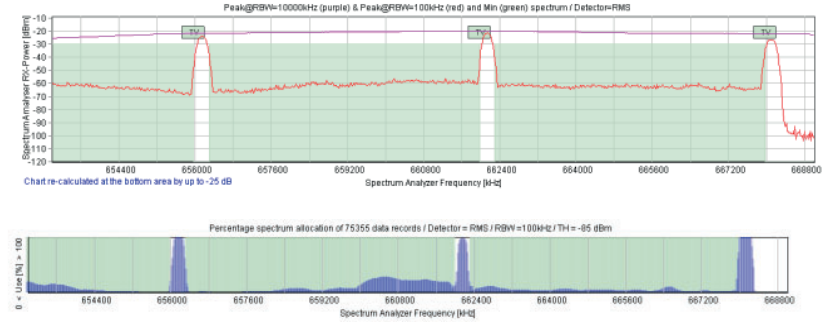

Figure 22-23: aggregated spectrum from $653-669 \mathrm{MHz}$ ( $2^{\text {nd }}$ day, 75354 data records)
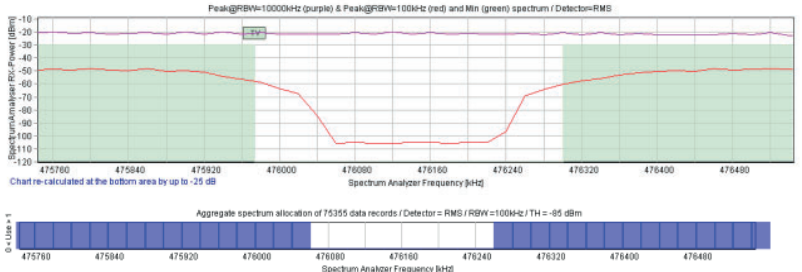

Figure 24-25: aggregated spectrum from 475.744- $476.544 \mathrm{MHz}$ ( $2^{\text {nd }}$ day, 75354 data records)

Location 1 - TV Globo booth

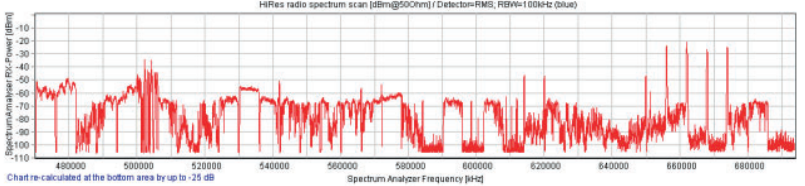

Figure 26: $1^{\text {st }}$ scanner, aggregated spectrum from $470-694 \mathrm{MHz}$ ( ${ }^{\text {nd }}$ day, 45154 data records)

Location 2 - international technical area

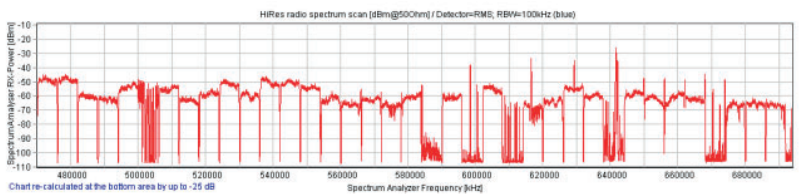

Figure 27: $2^{\text {nd }}$ scanner, aggregated spectrum from $470-694 \mathrm{MHz}\left(2^{\text {nd }}\right.$ day, 30200 data records $)$

Location 1 and 2

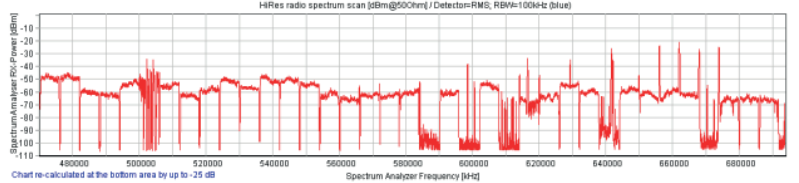

Figure 28: aggregated spectrum of both locations from 470-694 MHz ( $2^{\text {nd }}$ day, 75354 data records)

Maximum recorded receive level at Location 1 and 2

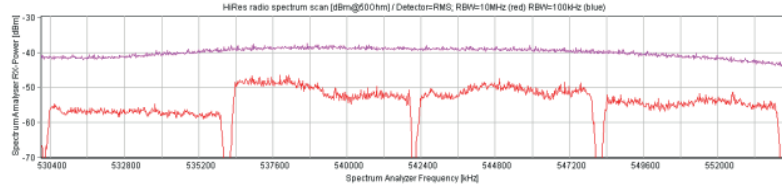

Figure 29: spectrum recording in a resolution bandwidth of $200 \mathrm{kHz}$ (red) and $10 \mathrm{MHz}$ both with RMS detector level of the TV stations must be expected for PMSE antennas that deviate from vertical polarization.

Bandwidth to be taken into account for the calculation of intermodulation

Audio PMSE receivers known to us have a frontend bandwidth of probably more than $24 \mathrm{MHz}$. However, several receivers are often connected to a common antenna via an active splitter. This non-linear transmission block must also be taken into account.

The users and frequency coordinators of Audio PMSE must carefully consider this scenario.

Aggregated scan from November 2018

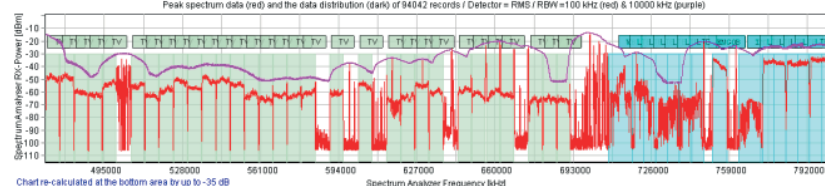

Figure 30: spectrum recording in frequency domain

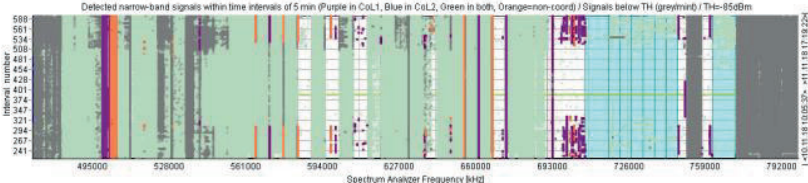

Figure 31: spectrum recording in frequency and time domain

Aggregated scan from August $8^{\text {th }}, 2019$
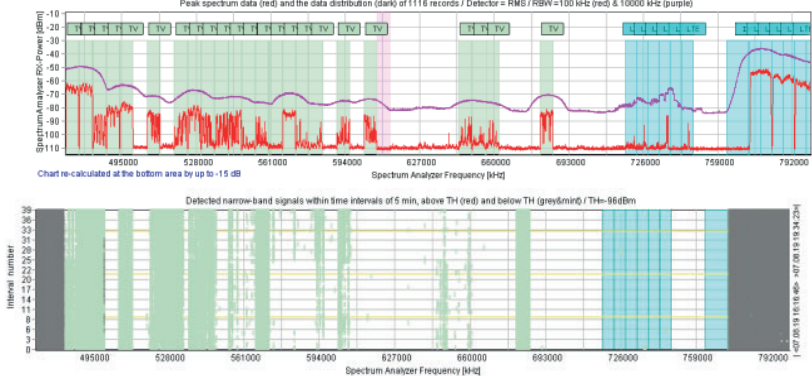

Figure 32-33: spectrum recording in frequency and time domain

Comparison of frequency use by TV and IMT (application of the land mobile service) and possible changes

Interesting is the use of the spectrum outside the production of events. Therefore, in this section we will compare the frequency use in the band 470 to $800 \mathrm{MHz}$ during $\mathrm{F} 1$ production in October 2018 with an additional scan from August 2019. Below in the figures 30 to 33 one can see the actual spectrum access of broadcast and mobile communications and possible changes in their operation.

\section{Restriction of this evaluation}

Both spectrum recordings took place at different locations and with different antenna heights. It is therefore possible that the spectrum recording in August may show an incomplete TV and IMT coverage. Another indicator for a worse antenna position of the second scan is the level of most signals reduced by more than $10 \mathrm{~dB}$. 
Table 6 - Spectrum recordings

\begin{tabular}{|c|c|c|c|c|l|}
\hline Date & $\begin{array}{l}\text { Number of } \\
\text { TV sections }\end{array}$ & $\begin{array}{l}\text { TV } \\
\text { MHz] }\end{array}$ & $\begin{array}{l}\text { Number of } \\
\text { IMT sections }\end{array}$ & $\begin{array}{l}\text { IMT } \\
\text { [MHz] }\end{array}$ & $\begin{array}{l}\text { Scan } \\
\text { time }\end{array}$ \\
\hline $\begin{array}{c}\text { November } \\
2018\end{array}$ & 31 & 186 & 12 & 60 & $\begin{array}{l}\sim 3 \\
\text { days }\end{array}$ \\
\hline $\begin{array}{c}\text { August } \\
2019\end{array}$ & 25 & 150 & 12 & 60 & $\begin{array}{l}\sim 3 \\
\text { hours }\end{array}$ \\
\hline
\end{tabular}

Both sets of scans show that the UHF TV band is intensively in use by digital TV and IMT. During the event and content production the 'white spaces' are in temporarily use by PMSE.

To illustrate a little the complexity of content production teams working at the event, figure 34 shows the equipment installed on the ground, figure 35 the helicopter video recording, figures 36 and 38 show different teams working, figure 37 the flying helicopter and a crane boom behind the pit lane. Figures 39-40 shows some satellite antenna (at compound) and other antenna arrays (next to the pit lane).

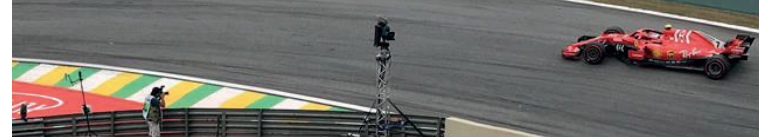

Figure 34: equipment of the event production installed on the ground, a photographer and the racing car

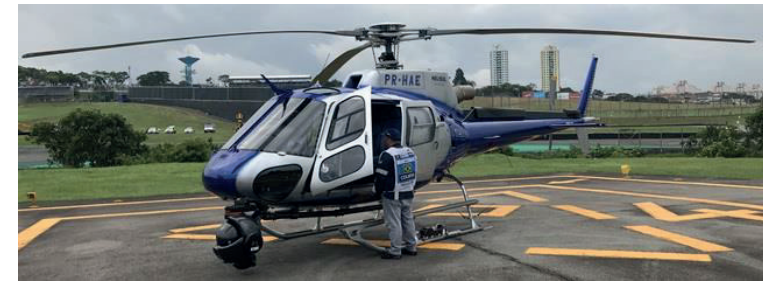

Figure 35: view of the helicopter that was used for the flying video recording

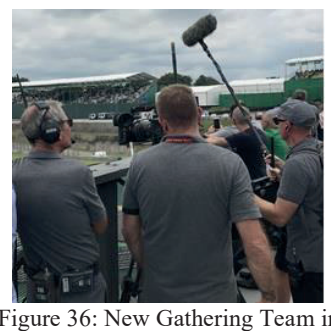
operation

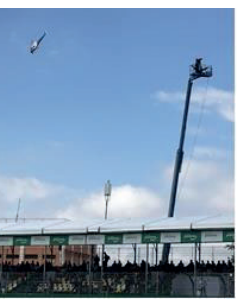

Figure 37: Helicopter and camera on a crane boom

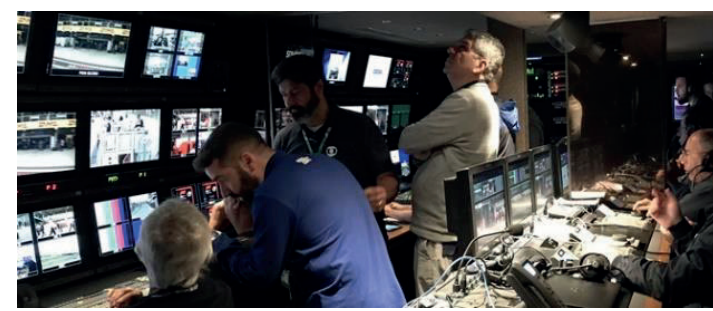

Figure 38: view into an on-site content production vehicle

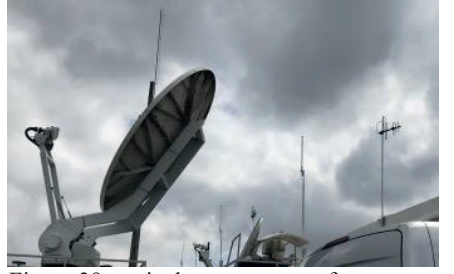

Figure 39: typical arrangement of antennas for team and satellite communication

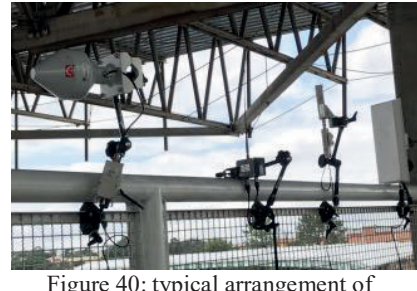

Figure 40: typical arrangement of antennas for further radio systems of the event

\section{IV - DISCUSSIONS AND CONCLUSIONS}

In this RF Scanning, we show that the number of wireless PMSE microphones use increased in the Formula One GP Brazil from 2014 to 2018, like in the Italian GP. This last measurement procedure was the most detailed scan to date in the wireless PMSE microphones band at Brazilian F1 GP. The figure 41 shows a re-draw of figure A.2 of ETSI TR system document for PMSE microphones [7] and the convergence to 0.34 links $/ \mathrm{MHz}$ density in large spectrum consistent with our recorded data to this event.

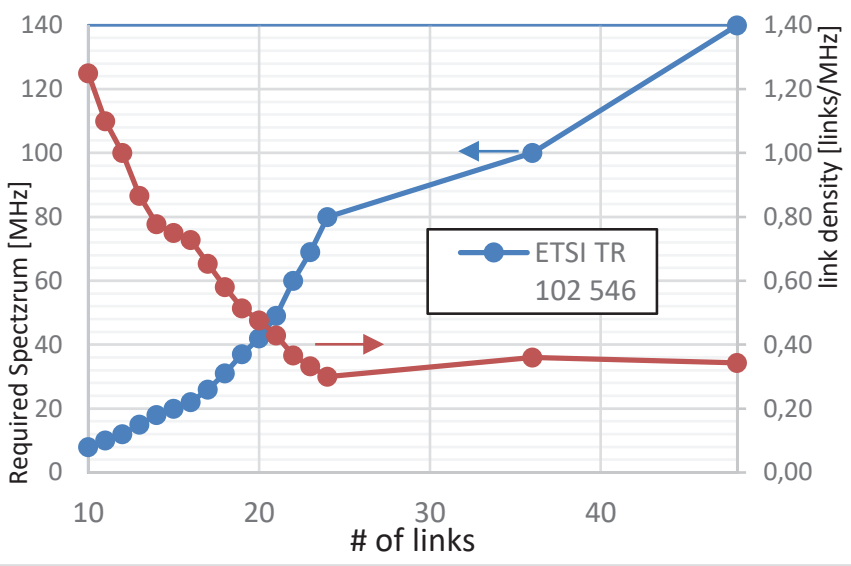

Figure 41: Required Spectrum and link density vs. Number of links

During the Brazilian Formula One event the operation of PMSE in the gaps between television channels was observed and is assessed as a critical scenario. Considering the high density of registered TV channels, non-linear transmission blocks must also be taken into account and users and frequency coordinators of Audio PMSE must carefully consider this scenario too.

Only a summary of all available information in relation to this work is presented in this work. Those who require further, more detailed information should please contact APWPT via office@apwpt.org.

\section{ACKNOWLEDGMENTS}

Comparable to many previous spectrum recordings, this activity was only possible with intensive technical and logistical support. Among many others we extend warm thanks to the following teams and people: Formula One, professors Ivan Roberto de Santana Casella and Stilante Koch Manfrin of Federal University of ABC, RAI Italy and Sennheiser.

The authors gratefully acknowledge the Globo TV and the collaboration of the involved staff to use their services and facilities for conduction of this research.

\section{REFERENCES}

[1] EuMW, "European Microwave Week," 10 August 2019. [Online]. Available: https://www.eumweek.com/.

[2] International Broadcasting Event, "IBC Show," 13 September 2018. [Online]. Available: https://show.ibc.org/. 
[3] P. Seeger, "IBC SHOW 2018 - 10 years of APWPT", 10 August 2019. [Online]. Available:

https://www.apwpt.org/downloads/ibc2018_frequencies-f1-gp.pdf.

[4] ETSI, "Programme making \& special events (PMSE)," 11 August 2019. [Online]. Available:

https://www.etsi.org/technologies/pmse.

[5] Wikipedia, "Autódromo José Carlos Pace," 08 August 2019. [Online]. Available:

https://de.wikipedia.org/wiki/Autódromo_José_Carlos_Pace.

[6] FIA, "Highs and lows - which F1 track has the most elevation changes?" 10 August 2019. [Online]. Available: https://www.formula1.com/en/latest/features/2016/10/highs -and-lows---which-f1-track-has-the-most-elevationchanges-.html.

[7] ETSI TR 102 546, Electromagnetic compatibility and Radio spectrum Matters (ERM); Technical characteristics for Professional Wireless Microphone Systems (PWMS); System Reference Document, V1.1.1 (2007-02), Sophia Antipolis, 2007.

[8] ETSI, "4th Generation (LTE)," ETSI, 20 August 2019. [Online]. Available: [Accessed 20 Aug 2019]. https://www.etsi.org/technologies/mobile/4g.

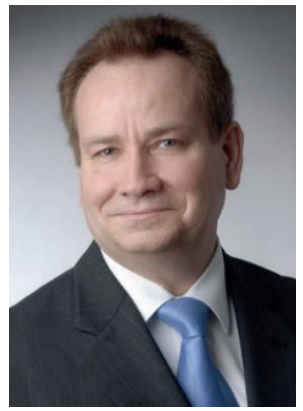

Matthias Fehr is a graduated engineer in Industrial Electronics, Dipl.-Ing. (FH), 1985, Microprocessor Systems, Dipl.-Ing. (FH), 1989 and Biomedical Technology and Bio-Cybernetics, Dipl.-Ing. (TH), 1990. From 1984 to 1990 he was the head of the Department for Electronic Tool Building and Prototypes in the Institute "FOE" of University Ilmenau. From 1990 to 2001 he was the head of the Aeronautical Radio Development Department at Walter Dittel GmbH.

From 2001 to 2008 he worked as a technical coordinator for radio frequency projects in the Research Division of Sennheiser Electronic $\mathrm{GmbH}$. Since 2008 he is President / Chairman of Executive Board of APWPT, the world-wide working Association of PMSE users and PMSE manufacturers.

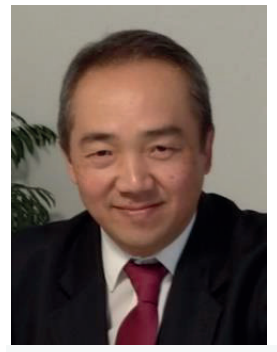

Mario Minami received BSc degree in Physics (1990) from IFUSP, Institute of Physics of the University of São Paulo, BSc degree in Pedagogy (2009) from Nove de Julho University, MSc (1993) and PhD (1998) in Electrical Engineering from the Polytechnic School of the University of São Paulo, EPUSP. Since 1993 at now, he is an associated researcher at the Signal Processing Laboratory (LPS) at EPUSP.

Since 2010 he is Associate Professor of Information Engineering at UFABC, CECS, in the Multimedia Communications Group. Member of Signals and Systems Laboratory (2012) and the Cybernetic Pedagogic Robotic group (2016) at UFABC. Member of IEEE Signal Processing Society and Acoustical Society of America. His research interests are in Speech Signal Recognition and Synthesis, Speech Analysis and Coding, Digital Audio Modeling, Image Processing in Digital Games and Robotics in Education

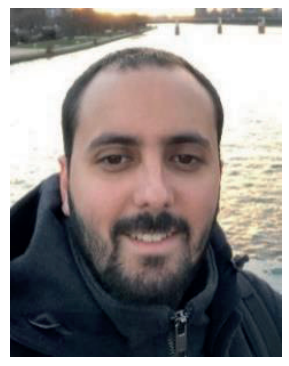

Felipe Filgueiras is a Telecommunications Technician (2012) and Telecommunication engineering student. He has been working in the RF area for 8 years and since 2013 at TV Globo where he is the coordinator of DTPD division.

His division is responsible by coordination of all frequencies used for each sporting events of the Globo Group and regularizing them with the competent regulatory agencies.

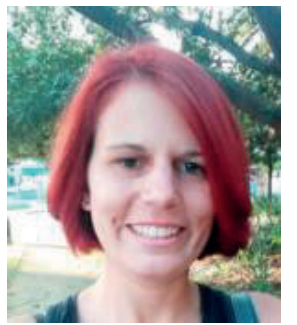

Pia Seeger received BE degree (2016) at Beuth Hochschule für Technik Berlin, Germany, MSc in Information Engineering (2017) at University Federal of ABC (UFABC), Brazil, and Master of Engineering (2018) at Beuth Hochschule für Technik Berlin, Germany. She worked in Bene Lux event technology (2012), Steffens and Hecht Stahlbau GmbH (2013), satis\&fy AG (2015) all in Hamburg, Germany.

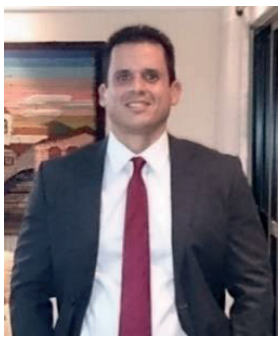

André F. Ponchet obtained the titles of Electrical Engineer from the Federal University of Ceará (2002), Master in Telecommunications

Engineering (2006) and $\mathrm{PhD}$ in Electrical Engineering (2016) from the State University of Campinas. He have been working on RF IC design since 2009. In 2017 started to work as an assistant professor at the Center for Engineering, Modeling and Applied Social Sciences at the Federal University of ABC. Dr. Ponchet interests include: analog and RF Integrated circuits design, broadband amplifiers for millimeter wave applications, RF transceiver architectures, optoelectronics and silicon integrated photonics.

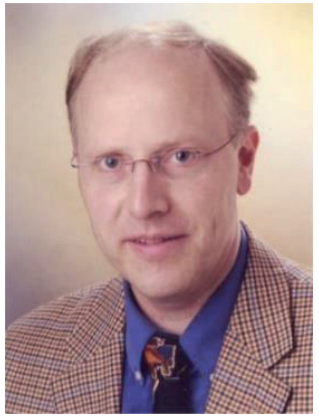

Georg Fischer (M'01-SM'08) received the Diploma degree in electrical engineering from RWTH Aachen University (1992), and the Dr.-Ing. degree in electrical engineering from the University of Paderborn, (1997) both in Germany. From 1993 to 1996, he was a Research Assistant with the University of Paderborn, working with adaptive antenna array systems. From 1996 to 2008, he performed research with Bell Labs, Lucent (later Alcatel-Lucent, now NOKIA) in GSM, UMTS systems.

Since April 2008, he has been a Professor for electronics engineering with the University of Erlangen-Nuremberg FAU. He holds over 50 patents concerning microwave and communications technology. His research interests are in transceiver design, analog/digital partitioning, converters, enhanced amplifier architectures, duplex filters, metamaterial structures, GaN transistor technology and circuit design, and RF microelectromechanical systems (MEMS) with specific emphasis on frequency agile, tunable, and reconfigurable RF systems for software-define radio (SDR) and cognitive radio (CR) applications. His new research interests concentrate on wireless multimedia transmission like PMSE (Program Making and Special Events). He is a Senior Member of the IEEE Microwave Theory and Techniques Society (MTT-S)/Antennas and Propagation Society (APS)/Communications Society (COMSOC)/ Vehicular Technology Society (VTC)/ IEEE Engineering in Medicine and Biology Society (EMBS) and member of VDE-ITG and European Microwave Association (EUMA). 